week for himself. I passed No. 13 with ease. No trace remains of the stricture, and he has no symptoms whatever.

CASE \pm was that of an Inclian officer, brought to me by $\mathrm{Mr}$ Daubeney, of York-place, Portman-square. He has suffered from stricture about twelve years; has experienced several attacks of retention, and submitted to several courses of dilatation, the benefit of which has only been temporary. Whenever he takes a glass of beer or of other stimulant, or passes his own instrument (which he has long been in the habit of doing) with any difficulty, an attack of retention follows.

On examination I found three strictures; one at three-quarters of an inch from the orifice, one at three inches, and one at five inches and a half. He had to return to India in a month, and was very desirons to obtain more permanent relief than dilatation had afforded him. On the 16 th September, 1858, I divided all these, as in the preceding case, and passed a fullsized flexible instrument into the bladder. As the bleeding was a little free, I removed it subsequently, and passed a large silver catheter in its place. He went on extremely well, a little oozing of blood occurring at times during four days.

He went out of town on business on the fourteenth day after the operation, Nos. 11 and 12 having been passed daily.

On Oct. Sth he returned, and I passed the same instruments with ease.

On the 23rd he sailed for India, passing No. 11 for himself withont the slightest difficulty.

I have recently heard from this gentleman that he passes occasionally the No. 11; that he has no symptoms whatever, but is perfectly well.

Case 5.-A gentleman, aged about thirty-six, was brought to consult me by Mr. Walford, of Reading, in August, 1858. His history was a long one of severe urethral obstruction, which of late had been increasing so much, that the consequences were almost unendurable. The narrowing, which was just anterior to the scrotum, was so tight, and so extremely sensitive, that, except under chloroform, I could get nothing through it, and then only the smallest probe. The hard and dense cha racter of the stricture, and the failure of previously-applied dilatation, decided me to recommend internal incision.

In the following month he came up to town for the purpose. The former conditions were now aggravated by abscesses in the penis, which had formed in the interval. Mr. Walford, having given the patient chloroform, I first evacuated matter from each corpus cavernosum by an incision on either side, then passed a very slender director through the stricture, dividing it from before backwards, and then completing the operation by an incision made in the reverse direction, after which $I$ passed a No. 8. No unpleasant consequences of any kind occurred, except a single shivering fit on the day following. He was a man of highly nervous temperament, and recovered his strength less rapidly than most patients, The operation was performed Sept. 2nd, 1858, and he left town on the 1st of October, in perfect health and No. 9 passing easily. The fistula resulting from the incision had not quite healed, but did so during the following month.

July, 1859. - I have just heard from Mr. Walford that the patient was perfectly well, and had recently passed No. 9 with perfect ease.

CASE 6. - A gentleman, aged sixty-eight, brought to me from Cornwall by Mr. Pryce, of Redruth. Without detailing a long history of forty years' stricture, it is sufficient to say that he had been the subject of repeated courses of treatment of various kinds, both in London and in the country, including one course of dilatation, in 1857 , by myself, which had been tolerably successful at the time, but the effects of which were only temporary, in spite of his own ability to pass instruments exceedingly well for himself.

In August, 1858, I saw this patient again, and could not succeed in dilating from No. 2 to No. 4, without incurring attacks of retention. In short, with great care, little or no progress was made.

Accordingly, on September 2nd, I performed internal division, Mr. Wilkinson, then house-surgeon of University College Hospital, rendering me assistance. I passed No. 9 afterwards.

On the 20 th of the month he returned to Cornwall, passing No. 9, with ease, for himself.

Oct., I859. - I have just heard from this gentleman, in reply to my inquiries, that he passes his instrument (No. 9) regularly, and that he is perfectly well in all respects, not having enjoyed such comfort for many years.

Wimpole-street, Cavend'sh-square, 1859 .

\section{REPORT OF CASES OCCURRING IN INDIAN PRACTICE.}

BY JAMES KEESS, M.B.,

ASSIST.-SERGEOX, LIFT WING 52ND REGT. HADRAS NATTTE IXFANTRT.

HEPATITIS ACUTA

THE subject of the following ease is an Indo-British drummer, of twenty-three years of age and eight years' service, of tem. perate habits and phlegmatic temperament. Previously to his arrival at this station in December, 1857, he had enjoyed good health. In October, 1858, during the malarious season, ${ }^{*}$ he became subject to quotidian intermittent fever, which yielded readily to the influence of quinine.

The points of interest in this case are, the insidious formation of an hepatic abscess in a native of India of temperate habits, its relation to a previous attack of intermittent fever, and its favourable termination.

Dec. $6 \mathrm{th}, 1858$. - Readmitted, with laxity of bowels ; evacuations liquid, frothy, and streaked with blood, and passed with much griping. He states that the diarrhoea commenced yesterday morning, and became much worse last night. Ordered tincture of opium, forty minims; water, one ounce : to be taken immediately. - Two P. Mr.: Since one P.M. he has been suffering from severe spasmodic pain in the epigastric region, which is increased on pressure and on taking a full inspiration. Has had two motions since morning, of the same character as that described above. Is unable to lie on his back, but can manage to lie on either side. Pulse 108, and soft; tongue thickly furred, white, edges florid and indented; skin warm. Ordered castor oil, one ounce; tincture of hyoscyamus, ten minims; water, one ounce : to be taken immediately. Fomentation to epigastric region. - Five P.M. : At three P.M. he vomited up a little of the oil, and shortly afterwards he voided a loose and copious motion, consisting almost entirely of reddishcoloured pus. States that he experienced great relief after the motion, but feels aguish now, and has therefore covered himself up with a blanket. Pulse 106, and soft. To have a meal of sago.

7th.--Seven A.M.: Pulse 96, and soft; tongne thickly covered and white; bowels moved twice during the night, and immediately before each evacuation he was seized with severe spasmodic pain in the epigastric region. Evacuations consist en tirely of red-coloured pus, and on the surface they are covered with a thin film of green-coloured bile in two places. There is tenderness on pressure in the epirastric region, but there is no enlargement of the liver detectable in this part. Patient says that for the last five days he has felt a deep-seated weight at the pit of the stomach, and that he has felt chilly at night-fall so much so that he thought he was subject to fever. Ordered to lie in a semi-recumbent position, and to continue quiet. To have a slice of toasted bread and a cup of tea at eight A.M. Five P.M.: Took a meal of arrowroot congee at one P.M. Pulse so, soft; skin cool; bowels moved twice, at nine and ten A.M. Evacuations consist of dark-coloured feculence; a little reddishcoloured pus is seen floating on the surface of the motions. States that he experienced a little griping pain in the epigastric region previous to and during defecation. Firm pressure over that region produces no pain. To have a meal of sago congee at seren $P . M$

10th. - Since last report his evacuations have been feculent and formed, and voided without any pain. Tonoue clean; pulse natural; skin cool; appetite good; sleeps well at night. Diet to be gradually increased.

11th. - One healthy, feculent evacuation this morning. No tenderness in the epigastric region on pressure. Functions normal.

14th.--One healthy, feculent motion daily. No tenderness on pressure in the hepatic region. Appetite good; tongue slightly furred, brown.

Discharged convalescent.

\section{SQUINTING.}

J. A-_, aged twenty-six years, of spare habit of body and nervons temperament, an inhabitant of Mysore, and a good. Persian scholar; is employed as private secretary to the Amildar of Seringapatam, and tutor to his children. Has been

* The arerage annual temperature of this station is $76^{\circ}$. It is beliered to be a malarious locality, from the great prevalence of intermittent and remittent fever. 
married for the last six years. Had an attack of gonorrhcea shortly before his marriage, for which he was salivated by a hakeem. After this he became very weak, and lost flesh. About fourteen months ago, as was his usual habit in the morning, he took up a book to read; but, to his great surprise, he found that he was obliged to turn his head a little to the left side to enable him to distinguish the words before him. He then looked into a glass, and found his left eye turned inwards towards the nose. On looking at objects beyond a distance of ten yards, he found that they were doubled. A week afterwards he consulted an apothecary, who blistered his left temple, and recommended him to wear warm clothing, and keep his feet warm. The blister was kept open for a month without producing any benefit. He was then treated with purgatives and with mercury, which salivated him. He then discontinued all treatment, as nothing did him any good.

About four months ago, and ten from the commencement of the squinting, he came to me from Mysore for advice. He was emaciated and weak; appetite bad; pulse 100, and small when sitting. He was also subject to occasional attacks of fever. $\mathrm{He}$ was recommended to improve his diet, to take a couple of half. boiled eggs daily (an article in which Mahomedans have great faith as a strengthening agent), to drink milk, and to partake of soups and animal food. He was also directed to close his right eye when reading and writing, and to wear in front of his left eye any opaque substance with a small circular aperture in its centre, so that he should not be able to see, except the pupil came in a line with the aperture. He seemed to be highly pleased with the advice; but before adopting it he consulted an eminent Mahomedan physician about the advisability of carrying out the treatment. Fortunately for him the hakeem recommended him to do so, and added at the same time that the advice given him was not in accordance with the principles of English medicine, which inculcated the use of blisters, \&c., but that it exactly tallied with the system of medicine as practised by Mahomedans, and gave me the credit of having taken an idea or two from Mahomedan books of medicine. After such encouragement from his co-religionist, the patient steadily followed the treatment recommended, and after the lapse of three months he presented himself to me a second time, his left eye acting in perfect accordance with its fellow. I find that he is not so spare as before. His appetite has somewhat improved; pulse, when sitting, 88 , and not so small; tongue rather large and furred, brown. Recommended to take a cupful of infusion of chiretta three times a day, and to continue the use of nourishing food.

P.S.-In The LANCET of April 30th, I gee Dr. Headland proposes to expunge from the contemplated British Pharmacopoia, cannabis and chiretta. As the former is prescribed in India for various diseases, and the latter is employed as a substitute for gentian in nearly every Government hospital in the Madra: presidency, I question whether Indian medical officers would vote with Dr. Headland in getting rid of these two drugs. As regards the other seventy-two, there can be no doubt that most medical practitioners would be glad to see them removed from the proposed British Pharmacopcia.

French Rocks, July, 1859.

ON A

\section{CASE OF CONGENITAL ENCEPHALOCELE. By CHARIES VINES, Esq., M.R.C.S.}

THe child, a female, of whom the accompanying sketch is a representation, was born on the 10th of July, 1859, and lived nearly five weeks. It was extremely feeble at birth, and continued so subsequently, was unable to suck, and swallowed with difficulty. The mother squeezed a little of her milk into the child's mouth, and fed it occasionally with a little thin arrowroot in a teaspoon. The effort of swallowing brought on convulsions, which lasted from a quarter of an hour to an hour, the face and extremities becoming livid. The child gradually wasted, became anæmic, and died on the 13th of August following.

The tumour, which projected from the posterior part of the cranium, measured nine inches in its vertical circumference, and was slightly furnished with hair at the upper part. On dissection, it was found covered at the upper portion by scalp, at the lower by skin merely; beneath this were dura mater and the usual coverings of the brain, extremely attenuated. The greater portion of the tumour consisted of cerebellum; but on cutting into it about two ounces of straw-coloured fluid escaped.

The opening through which the tumour had passed was an aperture about three-quarters of an inch square, large enough to admit the forefinger. It was in the centre of the occipital bone, and must have arisen from deficient bony development of this part.

The mother of the child stated to me that nothing remark. able happened to her during her pregnancy. She felt very little of the child during the last three months; was in labour nine hours. This was her second child. Both mother and father are healthy persons.

The midwife who attended the woman stated that the presentation was natural, and that the tumonr did not interfere materially with the progress of the labour. She also stated, that out of 5000 cases which she had attended, this was the only case of encephalocele which had come under her notice, and she had met with two cases only of spina bifida.

The case now related, though analogous to two others lately described in THE LANCET, differs from them in the contents of the tumour. In the cases referred to, the contents were prin. cipally fluid; in this instance, they were mostly solid.

A cast of this child's head has been taken, and placed in the museum of the Royal Berks Hospital.

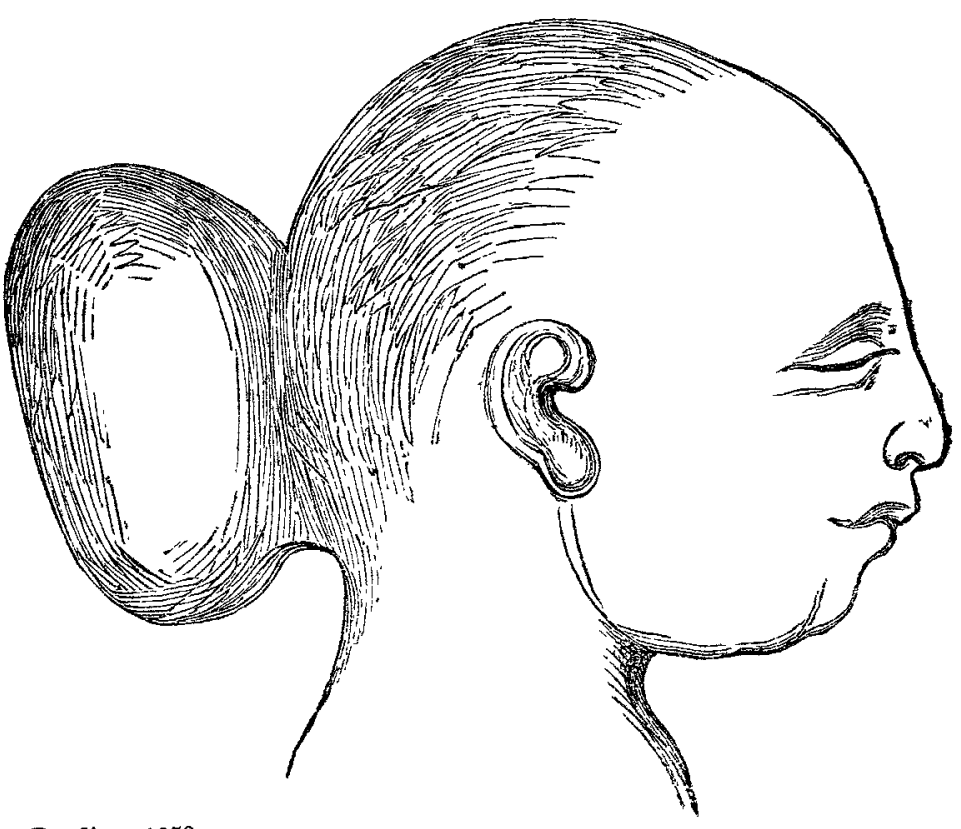

Reading, 1859.

\section{Altiror}

OF THE PRACTICE OF

\section{MEDICINE AND SURGERY IN THE}

\section{HOSPITALS OF LONDON.}

Nulla est alia pro certo noscendi via, nisi quam plurimas et morborum 'et Nulla est alia pro certo noscendi via, nisi quam plurimas et morborum et
dissectionum historias, tam aliorum proprias, collectas habere et inter se com. parare.-Mongagri, De Sed. et Caus. Morb., lib. 14. Procemium.

\section{KING'S COLLEGE HOSPITAL.}

NECROSIS OF THE END OF THE STUMP AFTER AMPUTATION OF THE THIGH FOR UNUNITED FRACTURE OF THE FEMUR.

\section{(Under the care of Mr. Fergusson.)}

IN our "Clinical Records" of the 3rd of September, (see also The LanerT, vol. ii., 1858, p. 117,) we referred to the case of a seaman who had been the subject of an ununited fracture of the thigh, which had resisted every mode of treatment that had been pursued to afford a chance of union of the broken bones. At the patient's urgent request, Mr. Fergusson performed amputation of the thigh on the 18th of June, and, as we then stated, the man made an excellent recovery, with 